\title{
Modeling using experimental design method of the physicochemical parameters of the water quality in Meknes city, Morocco
}

\author{
Ghariba Bouazza $^{l}$, Mohammed Assou ${ }^{2}$, Salah Souabi ${ }^{3}$ and El Houssine Chatri ${ }^{1}$ \\ ${ }^{1}$ Laboratoire d'atomique, mécanique, photonique et d'énergie, Faculté des sciences, Université Moulay Ismail, Département \\ de physique, Meknès, Maroc \\ ${ }^{2}$ Laboratoire de physique de la matière condensée et des énergies renouvelables, Faculté des sciences et des technologies, \\ Département de physique, Mohammedia, Maroc \\ ${ }^{3}$ Laboratoire de Génie des Procédés et Environnement, Faculté des sciences et des technologies, Département de génie des \\ procédés et de l'environnement, Mohammedia, Maroc
}

\begin{abstract}
This study was focused on the characterization of physicochemical parameters of drinking water, which are mainly involved during water treatment or analysis processes. we were interested in the application of the experimental design methodology, according to the method of Yates on the parameters that characterize the quality of drinking water in Meknes, Morocco. Six factors have been identified to control this quality. The influence of these parameters on the responses accommodated at the exit was highlighted. The derivation of a theoretical model has been realized and a series of experiments was performed. The analysis of our results, based on a statistical approach, was presented and the parameters that have a significant influence on the outputs have been identified. From these results, we can conclude that the input factors such as hardness, $\mathrm{pH}$, conductivity, residual chlorine and turbidity have a large influence on measured output response $\left(\mathrm{pH}_{\mathrm{s}}\right)$. Moreover, the theoretical and experimental results are very convergent which validate our studied model.
\end{abstract}

Keywords: ANOVA, Conductivity, Hardness, pH, Total Chlorine, Turbidity.

\section{Introduction}

The demand for water has increased significantly as a result of a combination of factors, such as population growth, the climate change and economic development. The drought experienced by Morocco has accentuated this demand even more.

The quality of drinking water is a challenge that must be constantly ensured to protect the public health. The national regulations put in place, in line with the recommendations of the World Health Organization (WHO), aims to ensure drinking water without the presence of chemical or biological substances[1,2]. This requires a number of controls to be carried out on the distributed water and the water discharged into the receiving environment. Effective analytical chemistry and microbiology of water are necessary to meet these challenges, relying on reliable, accurate and sensitive assay methods [3].

The development of high performance analysis tools, based on statistics and probabilities, is an advantage for their use in treatment of water [4]. They allow the analysis of the results and the deduction of the correlations between the different parameters of the systems [4].
For the planning of an acceptable and effective quantity of interest, we have screened the influencing parameters on the output $\mathrm{pH}$, for a sample that is the distributed water.

Experimental designs are a methodology of choice that allows to model and optimize the development of a product or an industrial process [5]. In a general way, this methodology will seek to determine and establish the links existing between input variables of the process and a quantity of interest, called answer. Variables, physical variables modifiable by the experimenter (factors), are supposed to influence the variations of the response. With the experimental design, we obtain the maximum of information with the minimum of experiences [6,7]

The screening technique, more specifically the Yates method where these plans constitute a tool for managing and organizing an experimental campaign whose purpose is to provide elements of information, easily interpretable [8]. 
The approach chosen for this research is to use Yates' experimental designs, which consider the effects of factors by reducing the number of trials to be performed. The methodology of these plans is distinguished by a significant reduction in the number of tests, while keeping a good precision [3,9]. We were interested in this study, in the application of the experimental plans more precisely the method of Yates.

The purpose of this work is the exploitation of this statistical approach in this field to facilitate the work of water analysis quality in Meknes city, Morocco, both in terms of the correct execution of the methods and the interpretation of the results.

\section{Materials and methods}

\subsection{Screening method}

Screening plans are designed to isolate influencing factors and examine the main effects of factors. This method is also called the main effect technique. screening study performed is carried out to identify the most influential factors on the studied response $(\mathrm{pH}$ of the output) $[11,12]$.

The screening method makes it possible to determine, among the factors identified by the experimenter, such as conductivity, turbidity, input $\mathrm{pH}$, temperature and hardness of entry, those which have a statistically significant influence on the variation of the response ( $\mathrm{pH}$ of the output). This implicitly leads to a simplification of the problem.

\subsection{Analysis techniques}

The various physicochemical parameters (PH, conductivity, turbidity, chlorine, water hardness and temperature) were analyzed according to the AFNOR (1999) standard [1,12].

\subsection{1 $\mathrm{pH}$ and Conductivity}

The $\mathrm{pH}$ of the solutions was measured using a Fisher Scientific $\mathrm{pH}$ meter "Accumet basic ab15 pH meter" equipped with an $\mathrm{Ag} / \mathrm{AgCl}$ combined glass electrode according to standard NF T 90-008 February 2001 (T 90-008) $[2,13]$. The calibration is performed using buffer solutions of $\mathrm{pH} 4.7$ and 10 at $20^{\circ} \mathrm{C}$. The accuracy of the measurement given by the manufacturer was $\pm 0.1 \mathrm{pH}$ unit.

The conductivity was measured using a conductivity meter brand "Conductivity meter intelligent $\mathrm{pH}$ YK2001PH" according to standard NF EN 27888 January 1994 (T 90-031) at $25^{\circ} \mathrm{C}[12,13]$.

\subsubsection{Turbidity}

Turbidity was measured using a turbidimeter according to the standard of NF EN ISO 7027 March 2000 (T 90-
033) $[1,10]$. As well as, this parameter was measured by the reflection of a light beam in water. Moreover, it was measured by an optical test that determines the light's reflectance (the unit of measurement is the "NTU" nephelometric units). This parameter depends on the suspended matters.

\subsection{Choice of factors and their modalities}

The specialists of water quality laboratory consider that six factors mainly influence the outlet $\mathrm{pH}$ of distributed water. These factors are of quantitative, controlled types such as Conductivity, turbidity, $\mathrm{pH}$ of inlet, temperature and hardness input. The levels of each factor in coded values and in real values, are given in Table 1 .

Table 1. Factors and selected levels

\begin{tabular}{|c|c|c|c|c|}
\hline \multirow{2}{*}{ Factors } & \multirow[b]{2}{*}{ Symbol } & \multirow[b]{2}{*}{ Unit } & \multicolumn{2}{|c|}{ Modalities } \\
\hline & & & Level1 & Level2 \\
\hline Hardness of entry & $T H_{E}$ & $\begin{array}{c}(\mathrm{mg} / \mathrm{L}) \\
\text { de } \mathrm{CaCO}_{3}\end{array}$ & $\begin{array}{c}15 \\
(-1)\end{array}$ & $\begin{array}{c}29 \\
(+1)\end{array}$ \\
\hline Residual chlorine & $c l_{R}$ & $(\mathrm{mg} / \mathrm{L})$ & $\begin{array}{l}0.13 \\
(-1)\end{array}$ & $\begin{array}{c}1 \\
(+1)\end{array}$ \\
\hline Temperature & $T$ & $\left({ }^{\circ} \mathrm{C}\right)$ & $\begin{array}{c}16 \\
(-1)\end{array}$ & $\begin{array}{c}20 \\
(+1)\end{array}$ \\
\hline Input $\mathrm{pH}$ & $p H_{E}$ & ------ & $\begin{array}{l}6.5 \\
(-1)\end{array}$ & $\begin{array}{c}8.5 \\
(+1)\end{array}$ \\
\hline Conductivity & $\sigma$ & $(\mu \mathrm{s} / \mathrm{cm})$ & $\begin{array}{l}430 \\
(-1)\end{array}$ & $\begin{array}{c}2700 \\
(+1)\end{array}$ \\
\hline Turbidity & Turb & (NTU) & $\begin{array}{l}0.23 \\
(-1)\end{array}$ & $\begin{array}{l}0.45 \\
(+1)\end{array}$ \\
\hline
\end{tabular}

\subsection{Experimental matrix}

The experiments were planned according to Yates method (matrix of model). Each column of this matrix corresponds to one factor, then each line corresponds to the number of experiments made, as well as each maximum value of such factor is replaced by $(+1)$ and the minimum values by $(-1)$.

$$
X=\begin{array}{llllll}
-1 & -1 & -1 & -1 & -1 & -1 \\
-1 & -1 & -1 & +1 & +1 & +1 \\
-1 & +1 & +1 & -1 & -1 & +1 \\
-1 & +1 & +1 & +1 & +1 & -1 \\
+1 & -1 & +1 & -1 & +1 & -1 \\
+1 & -1 & +1 & +1 & -1 & +1 \\
+1 & +1 & -1 & -1 & +1 & +1 \\
+1 & +1 & -1 & +1 & -1 & -1
\end{array}
$$

Model matrix 


\section{Results and discussion}

\subsection{Experimental plan and experimental results}

The following examples give the numerical values. The repeats to the eight experiments are indicated opposite, allowing the calculation of the effects. The experiments were planned according to the method of Yates (Table2).

Table 2. Experimental Design and Experimental Results

\begin{tabular}{|c|c|c|c|c|c|c|c|}
\hline \multicolumn{6}{|c|}{ Factors } & \multicolumn{2}{|c|}{ Responses } \\
\hline $\begin{array}{c}\text { Turb } \\
\text { Turbidity }\end{array}$ & $\begin{array}{c}T H_{E} \\
\text { Hardness of entry }\end{array}$ & $\begin{array}{c}p H_{k} \\
\text { Input pH }\end{array}$ & $\begin{array}{c}\sigma \\
\text { Conductivity }\end{array}$ & $\begin{array}{c}T \\
\text { Temperature } \\
\end{array}$ & $\begin{array}{c}c l_{\mathrm{h}} \\
\text { Residual chlorine }\end{array}$ & $\begin{array}{c}T H_{\bar{s}} \\
\text { output hardness } \\
\end{array}$ & $\begin{array}{c}p H_{S} \\
\text { output } \mathrm{pH}\end{array}$ \\
\hline-1 & -1 & -1 & -1 & -1 & -1 & 7 & 7.57 \\
\hline-1 & -1 & -1 & +1 & +1 & +1 & 23,8 & 7.35 \\
\hline-1 & +1 & +1 & -1 & -1 & +1 & 22 & 8.64 \\
\hline-1 & +1 & +1 & +1 & +1 & -1 & 24,2 & 8.72 \\
\hline+1 & -1 & +1 & -1 & +1 & -1 & 18 & 7.27 \\
\hline+1 & -1 & +1 & +1 & -1 & +1 & 20 & 8.2 \\
\hline+1 & +1 & -1 & -1 & +1 & +1 & 22 & 6.82 \\
\hline+1 & +1 & -1 & +1 & -1 & -1 & 26 & 7.49 \\
\hline
\end{tabular}

\subsection{Values of effects}

The calculation of the coefficients of the model, i.e. the values of the effects of the principal factors, allowed us to make a relative study of the factors with respect to their influence on the answer studied. The effects of the factors on the response $\mathrm{pH}_{\mathrm{s}}$ are presented in table 3 .

On the basis of the examination of the effects, the factors can be classified between them according to their ability more or less strong to vary this response. this type of study is very often translated graphically, by the use of histogram effects.

\subsection{Means effects Plot}

The average effect of a factor is defined as the variation of the observed or modeled response when the factor changes modality. For each studied factor, the averages of the results corresponding to each modality are linked by a line.

The average effect of a factor is defined from the observed or modeled difference of a response variable, when this factor undergoes a modality change. The scorecard and the average effect plot facilitate estimation and visualization of average effects.

The effects plot of the medium facilitates the return of the information. This is an undeniable asset of the methodological approach associated with the experimental plans.

All factors except residual chlorine influence the $\mathrm{pHs}$ as shown in Figure 1. This phenomenon is obviously seen in Pareto diagram of Figure 2.

\subsection{Pareto diagram}

It is possible to decompose the variation of a response from the contributions made by each of the factors in a model. The contributions of the factors are then ordered in ascending order and then represented as a bar chart. The contributions of the factors are then ordered in ascending order and then represented as a bar chart. The Pareto plot associated with a cumulative representation is complementary to the average effects plot. It makes it possible to determine the influential factors in descending order of contribution.

The Pareto $\mathrm{pH}$ chart of the output (pHs) (Figure 2) reinforces the predominance of the role factor $\left(\mathrm{pH}_{\mathrm{E}}\right)$ which appears first with a stick much larger than the others.

In this diagram, the effect of $\mathrm{pH}_{\mathrm{E}}$, Turb, $\mathrm{T}, \sigma$ and $\mathrm{TH}_{\mathrm{E}}$ is important and contributes to $40 \%$ of the response variations. In the other hand, the $\mathrm{Cl}_{\mathrm{R}}$ does not have a significant effect. So, it is necessary to verify if this factor was not involved in the effect of the response to remove it in the analysis of variance. 
Table 3. The effects of the analysed factors

\begin{tabular}{|c|c|c|c|c|c|c|c|}
\hline Factors & Constant & $\begin{array}{c}\text { Turb } \\
\text { Turbidity }\end{array}$ & $\begin{array}{c}\text { TH } H_{E} \\
\text { Hardness of } \\
\text { entry }\end{array}$ & $\begin{array}{c}p H_{E} \\
\text { Input } \\
\mathbf{p H}\end{array}$ & $\begin{array}{c}\boldsymbol{\sigma} \\
\text { Conductivity }\end{array}$ & $\begin{array}{c}\boldsymbol{T} \\
\text { Temperature }\end{array}$ & $\begin{array}{c}c l_{R} \\
\text { Residual } \\
\text { chlorine }\end{array}$ \\
\hline $\begin{array}{c}\text { The } \\
\text { average } \\
\text { effect }\end{array}$ & 6.55791 & 2.84091 & 0.02286 & 0.45 & 0.00016 & 0.10875 & 0.01149 \\
\hline
\end{tabular}

\section{Data means}

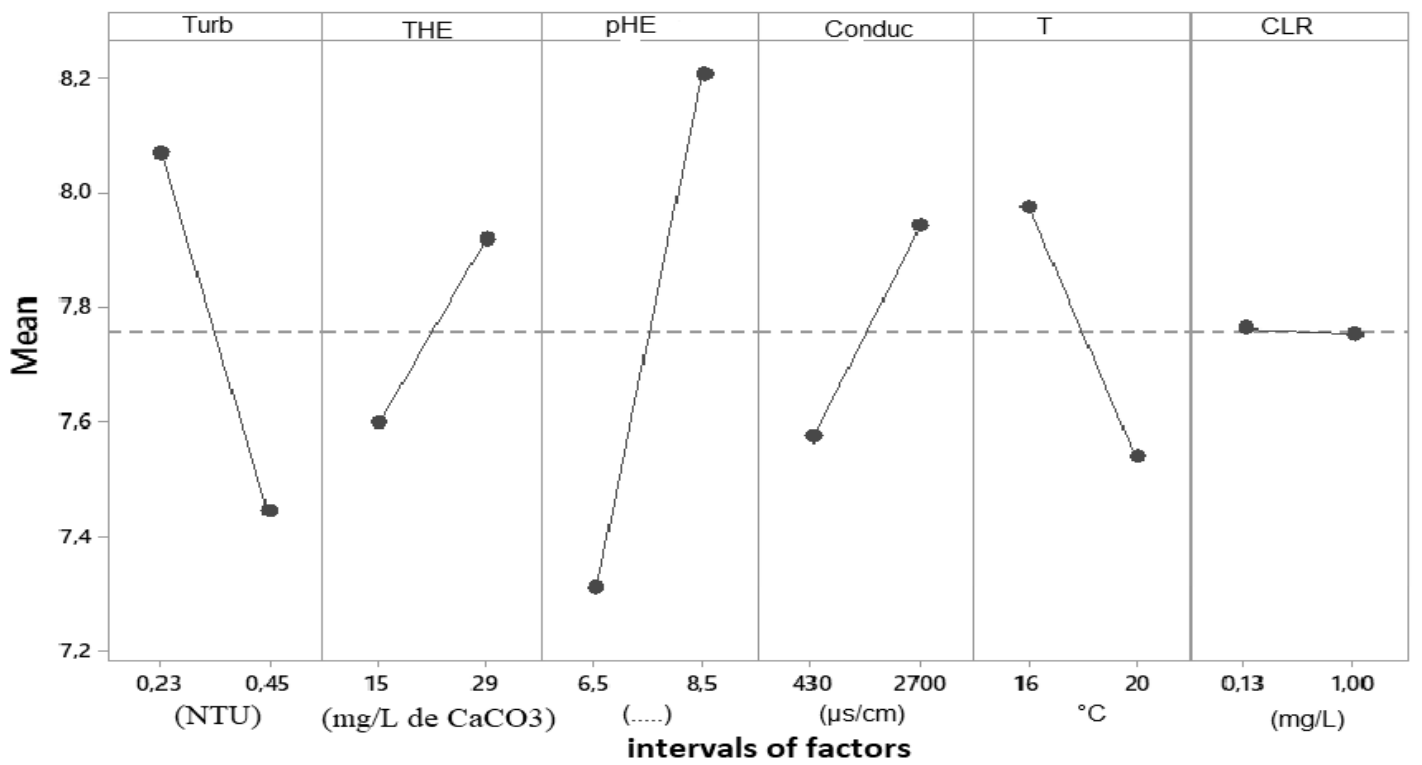

Fig.1. The effects of drinking water parameters on the response $\mathrm{pH}(\mathbf{p H s})$

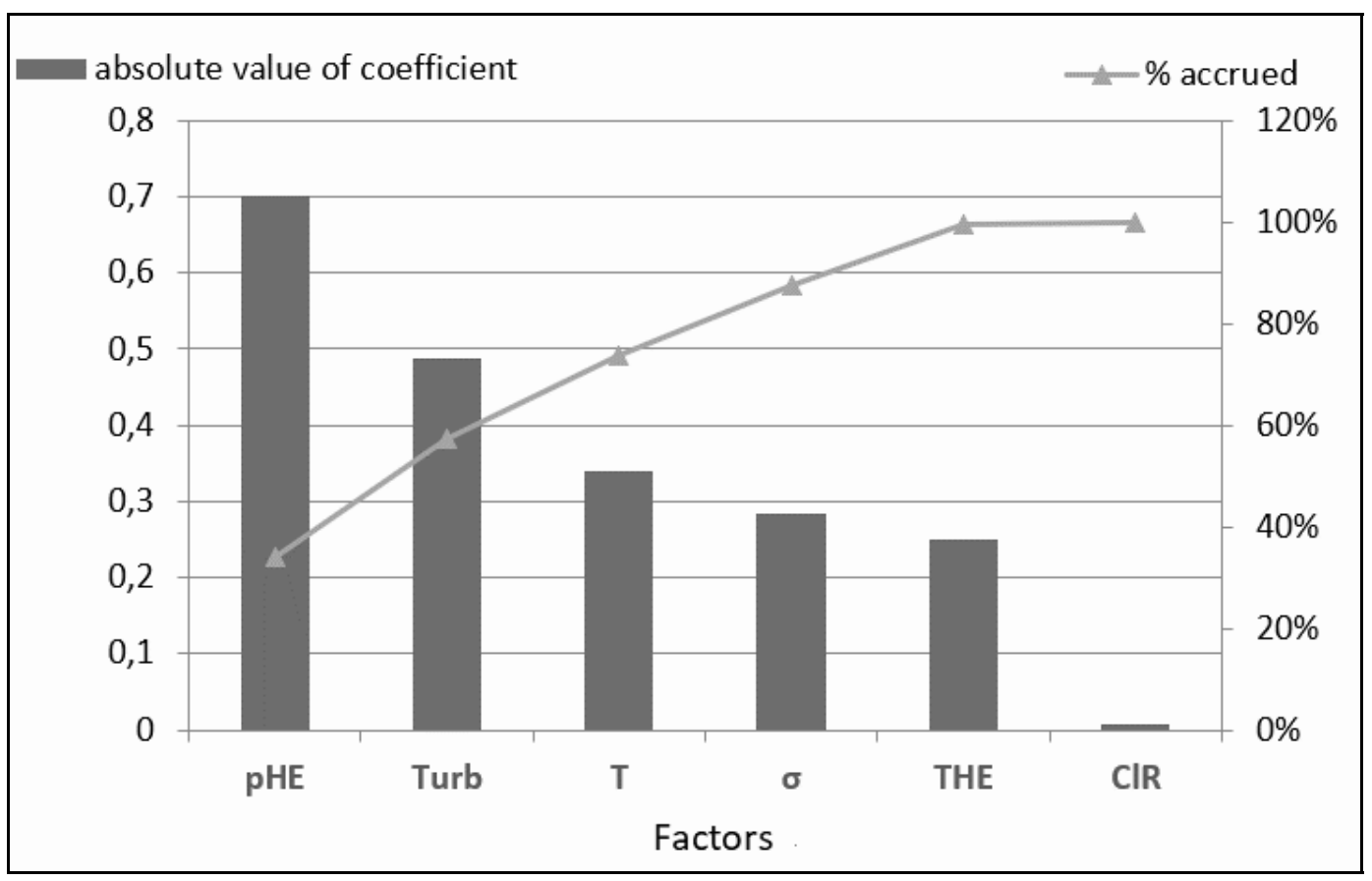

Fig. 2. Response pHs Pareto diagram 


\subsection{Statistical analysis of the model}

An analysis of variance performed on the results can identify the statistically significant of the model. The variance of the factors is obtained by calculating the squares sum of the gaps (SCE) divided by the number of degrees of freedom (Dof) associated with the factor $\mathrm{F}$ considered. The analysis of variance are presented in table 4.

The results of the experiment are statistically processed using ANOVA. Indeed, from the results obtained, a model of the first order was established. The main objective is to show the parameters that have the most effect on the studied $\mathrm{pHs}$ response.

In this study, the analysis of variance was conducted at a level of significance equal to $0.05(\alpha=5 \%, 95 \%$ confidence level). The results of the $\mathrm{pH}$ variance analysis are given in Table 4 . This table shows degrees of freedom (dof), sum of squares (SCE), mean square $(\mathrm{CM})$, test of $\mathrm{F}$ and probability ( $\mathrm{p}$ value). In general, a low probability (value of $\mathrm{p}<0.05$ ) gives information on the statistical significance of the corresponding response.

The results of the variance analysis (Table 4) show that the input $\mathrm{pH}\left(\mathrm{pH}_{\mathrm{E}}\right)$ is the factor that represents the large effect on the total change in output $\mathrm{pH}\left(\mathrm{pH}_{\mathrm{s}}\right)$, which explains a $p$ value of 0.0098 . The second factor affecting the response is turbidity with a $p$ value of 0.014 . Then, the effects of temperature, conductivity and hardness (T, $\sigma$ and THE) with a $\mathrm{p}$ value of 0.0198 , 0.0233 and 0.0263 , respectively. Finally, the effect of input chlorine $(\mathrm{ClE})$ has a $\mathrm{p}$ value greater than the threshold $(0.0955>0.05)$, and has no statistical significance for the variation of the $\mathrm{pHs}$.

\subsection{Mathematical model}

Regression analysis was used to develop a first order regression model for the $\mathrm{pHs}$ response to understand the effects of factors on response. The obtained $\mathrm{pHs}$ model is as follows:

$$
\begin{gathered}
\mathrm{pH}_{\mathrm{S}}=6.55791-(2,84091 \times \text { Turb })+\left(0,02286 \times \mathrm{TH}_{\mathrm{E}}\right)+\left(0.45 \times \mathrm{pH}_{\mathrm{E}}\right)+(0.00016 \times \sigma)-(0,10875 \times \mathbf{T})-(0,01 \\
\left.149 \times \mathbf{c l}_{\mathrm{R}}\right)
\end{gathered}
$$

\begin{tabular}{|c|c|c|c|c|c|}
\hline \multicolumn{6}{|c|}{ Analysis of variance } \\
\hline Source & $\begin{array}{c}\text { Dof } \\
\text { degrees of freedom }\end{array}$ & $\begin{array}{c}\text { SCE } \\
\text { sum of squares } \\
\end{array}$ & $\begin{array}{c}\mathbf{C M} \\
\text { mean square } \\
\end{array}$ & test of $\mathbf{F}$ & $\begin{array}{c}\text { p- Value } \\
\text { probability }\end{array}$ \\
\hline Regression & 6 & 3.25115 & 0.54186 & 13.82 & 0.0203 \\
\hline Turbidity (Turb) & 1 & 0.78125 & 0.78125 & 19.93 & 0.014 \\
\hline hardness $\left(T H_{E}\right)$ & 1 & 0.2048 & 0.2048 & 5.22 & 0.0263 \\
\hline Input pH $\left(P H_{E}\right)$ & 1 & 1.62 & 1.62 & 41.33 & 0.0098 \\
\hline Conductivity $(\sigma)$ & 1 & 0.26645 & 0.26645 & 6.8 & 0.0233 \\
\hline Temperature (T) & 1 & 0.37845 & 0.37845 & 9.65 & 0.0198 \\
\hline chlorine $\left(C l_{R}\right)$ & 1 & 0.0002 & 0.0002 & 0.01 & 0.0955 \\
\hline Error & 1 & 0.0392 & 0.0392 & & \\
\hline Total & 7 & 3.29035 & & & \\
\hline
\end{tabular}

Table 4. pHs output variance analysis

\subsection{Henry diagram}

Henry diagram allows the approximation of the mean and the standard deviation of the realizations of a Gaussian variable when only the distribution of values grouped in classes is available. The trend line of the point cloud, or "Henry's line" is represented in Figure 3.
The dispersed points are the line of equation $y=0.918 x+0.049$ and the coefficient of determination $\mathrm{R}^{2}$ equates 0.988 . The observed distribution can be model by a Gaussian law.

Since the cloud of points is close to a straight line, we can model the distribution observed by a Gaussian law. 
Henry diagram

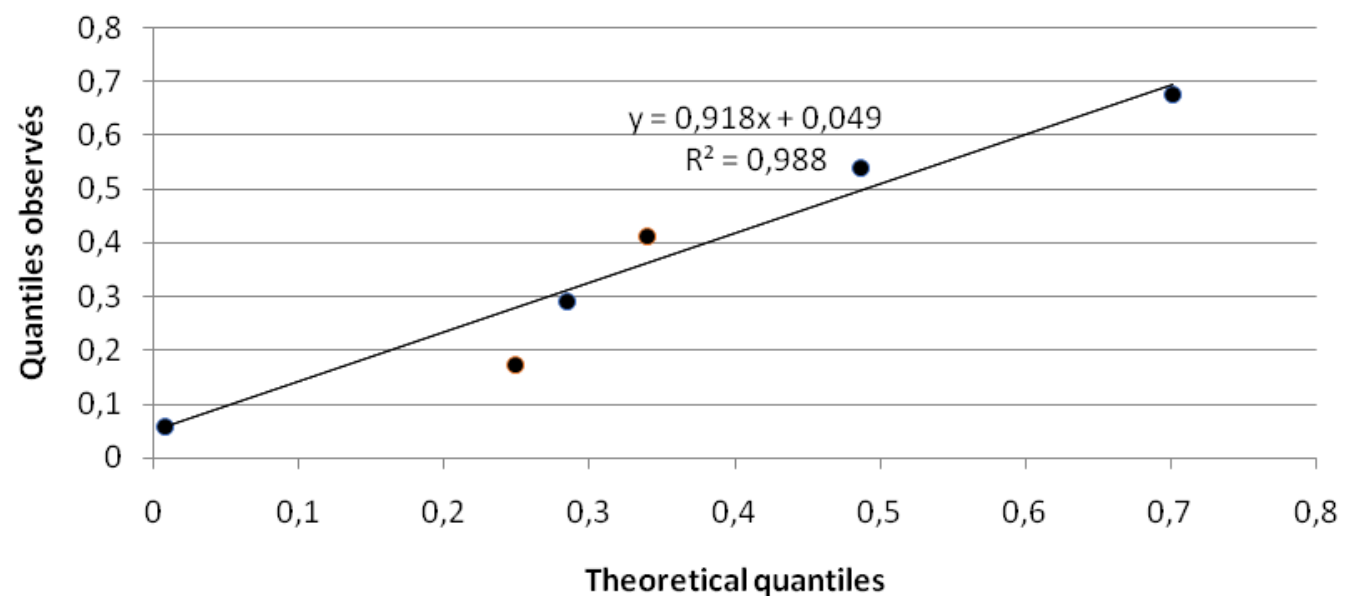

Fig. 3. Henry diagram of response pHs

\subsection{Diagram of responses}

The model, with excellent predictive capability, has a slope equal to unity and intersects the $\mathrm{Y}$ axis at the origin. Thus, the dots follow a linear pattern, indicating that the model fits the data well and predicts the pHs response in a meaningful way (Figure 4).

The coefficient of determination $\mathrm{R}^{2}$ indicates that the percentage variation of the pHs response is explained by the model, with a value of $98.8 \%$.
This coefficient characterizes the relationship between observed and predicted values, it is a direct measure of good fit. Indeed, this value of $\mathrm{R}^{2}$ is close to unity indicating a good qualitative agreement between experimentation and prediction.

Thus, the standard deviation (S) provides a measure of the extent of the response. It is equal to the square root of the variance of this response. This difference is low with a value of 0.081 .

It can be concluded that the two values $\left(\mathrm{R}^{2}\right.$ and $\left.\mathrm{S}\right)$ reflect the good descriptive quality of the model and the equation was correctly describes the pHs response.

\section{pHs}

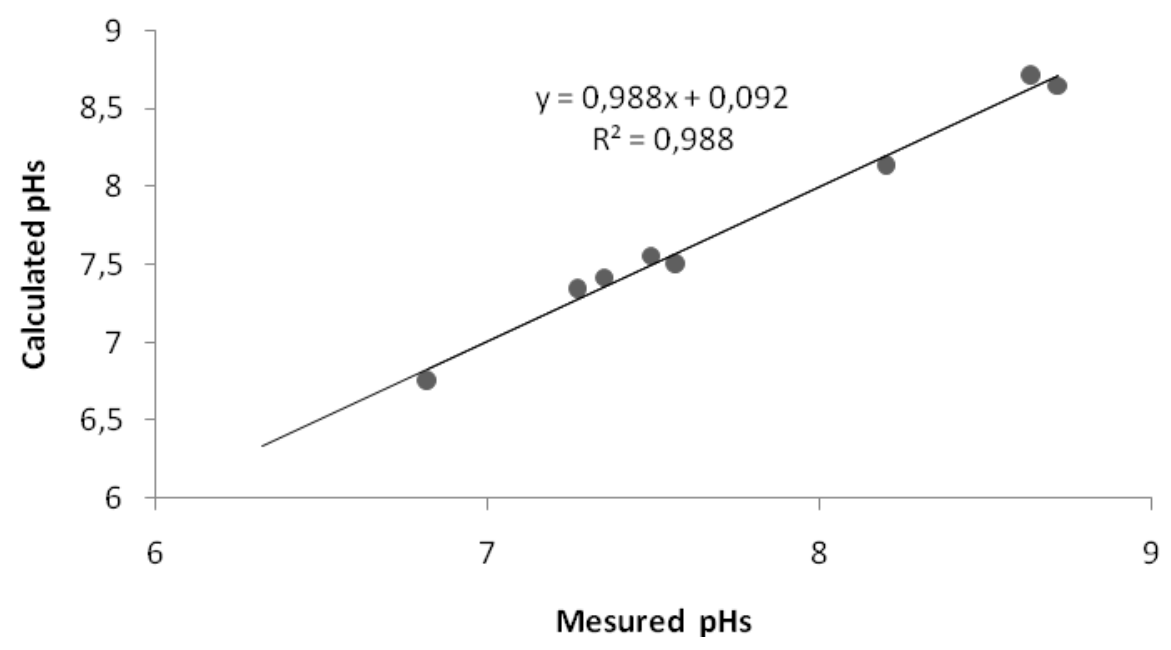

Fig. 4. Calculated values line according to the actual values of response pHs 


\section{Conclusion}

The presented study is part of the application of statistical and probabilities tools in the field of water quality treatment. More specifically, the aim of this study is to apply Yates experimental designs to show the effect of physico-chemical parameters $\left(\mathrm{pH}_{\mathrm{E}}\right.$, Conductivity, Hardness of entry, Residual chlorine and turbidity) on the output $\mathrm{pH}$ (pHs).

The Yates method has been used as a robust plan, which will provide the most significant factors at lower costs, with fewer experiments. The results clearly show that the experimental design is an appropriate method for screening the factors acting on the response under study. The Yates method that has been applied has led to a first-order model.

\section{References}

1. Rodier, J., Legube, B. \& Merlet, N. «L'Analyse de l'eau ». (2009).

2. Brezinski, K., Gorczyca, B. \& Sadrnourmohammadi, M. Ion-exchange for trihalomethane control in potable water treatment - A municipal water treatment case study in Rainy River, Ontario, Canada. Water Quality Research Journal 1- 19 (2018).

3. Goupy, J. Tutoriel des Plans d'Expériences. 74- 116 (2006).

4. Assou, M., Lachgar, B., Madinzi, A. \& Souabi. Removal COD in Tannery Waste Water: Modelling by the Experimental Design. J.Enginee.Sci.and Resea. Manage. 4, 102- 110 (2017).

5. Bouazza, G., Assou, M., Souabi, S. \& Chatri, E. Modelling by the experimental design for color removal ( absorbance at $254 \mathrm{~nm}$ ) from tannery wastewater. 148, 324- 328 (2019).

6. Bouazza, G., Assou, M., Souabi, S. \& Chatri, E. Elimination de la couleur des eaux usées de tannerie: Modélisation par la conception expérimentale.

7. Rabier, F. Modélisation par la méthode des plans d'expériences du comportement dynamique d'un module IGBT utilisé en traction ferroviaire. (Institut National Polytechnique de Toulouse,
The significant coefficients of this model are statistically related to the most influential factors; input $\mathrm{pH}\left(\mathrm{pH}_{\mathrm{E}}\right)$, turbidity, conductivity $(\sigma)$ and temperature $(\mathrm{T})$ as well as inlet hardness $\left(\mathrm{TH}_{\mathrm{E}}\right)$ on the response (output $\mathrm{pH}$ ).

The definition of the experiments that have been carried out has made it possible to build the exploration model of the experimental domain, this model being the key element of our strategy. This methodology has led us, at lower costs, to increase the accuracy in obtaining results and improving reliability.

Finally, this work is a preliminary study to extend it to wastewater, based on the three main parts:

$>$ The choice of an experimental method,

$>$ The gradual acquisition of results,

$>$ The results analysis.
8. Bouazza, G., Assou, M., Souabi, S. \& Chatri, E. Modeling through experimental design method of the physicochemical parameters of drinking water. communication, Journées doctorales: Innovation Tec

9. Karam, S. Application de la méthodologie des plans d'expériences et de l'analyse de données à l'optimisation des processus de dépôt. (LIMOGES, 2004).

10. Assou, M., Madinzi, A., Lachgar, B., \& Souabi, S. Removal Color From Tannery Waste Water: Modelling By The Experimental Design. I.J. Engenee. Sci. \& Resea.Techn. 6, 537- 548 (2017).

11. Assou, M., Lachgar, B., Madinzi, A. \& Souabi, S. Formed Sludge in Tannery Wastewater: Modelling by the Experimental Design. I.J.Sci. and Enginee. Investi. 6, 103- 107 (2017).

12. Kimbrough, D. E. Impact of local climate change on drinking water quality in a distribution system. Water Quality Research Journal 1- 14 (2019).

13. Husk, B. et al. Pharmaceuticals and pesticides in rural community drinking waters of Quebec, Canada - A regional study on the susceptibility to source contamination. Water Quality Research Journal 1- 16 (2019). 